\title{
Trakeal Tüp ve Laringeal Maske için Kaf Basıncı Ölçer Cihaz Tasarımı
}

\author{
Hakan ESER ${ }^{1}$, Kübra EVREN ŞAHIN², Savaş ŞAHİN ${ }^{3 *}$, \\ ${ }^{1}$ Biyomedikal Teknolojileri Anabilim Dalı, Fen Bilimleri Enstitüsü, İzmir Kâtip Çelebi Üniversitesi, İzmir, Türkiye \\ 2 İzmir Dr. Behçet Uz Çocuk Hastalıkları ve Cerrahisi Eğitim ve Araştırma Hastanesi, İzmir, Türkiye \\ ${ }^{3}$ Elektrik-Elektronik Mühendisliği, Mühendislik ve Mimarlık Fakültesi, İzmir Kâtip Çelebi Üniversitesi, İzmir, Türkiye \\ ${ }^{1}$ hakaneser29@ hotmail.com ${ }^{2}$ kubraevren@gmail.com ${ }^{3 *}$ sahin.savas@yahoo.com
}

(Geliş/Received: 12/03/2019;

Kabul/Accepted: 11/02/2020)

Öz: Bu çalışma trakeal tüp ve laringeal maske için kaf basıncı ölçmeyi sağlayan taşınabilir medikal cihaz tasarımı ve gerçeklemesini sunar. Geliştirilen cihaz, ameliyathane ve yoğun bakımlarda kullanılan pilot balon içindeki hava basıncının izlenmesini sağlayan taşınabilir bir medikal cihazdır. Trakeal tüp veya laringeal maske içinde ölçülen kaf basınç değerleri cihaz üzerinde bulunan ekrana ve hafıza kartına eş zamanlı aktarılabilir. Kaf pilot balonu içindeki hava basıncı izin verilen basınç değerleri aralığının dışına çıktığında sesli uyarı verir. Geliştirilen cihaz mikro denetleyici tabanlı bir gömülü sistem kartı ve baro-metrik basınç-ölçer kullanılarak gerçekleştirilmiştir. Basınç ölçümleri in-vitro olarak bebek ve çocuk fantomlar üzerinde test edilmiş, alınan gerçek verilerle istatistik analizi yapılmıştır.

Anahtar kelimeler: Endotrakeal tüp, laringeal maske, kaf basıncı ölçme, elektronik cihaz.

\section{Cuff Pressure Gauge Device Design for Tracheal Tube and Laryngeal Mask}

\begin{abstract}
This study represents the design and implementation of a portable medical device that provides cuff pressure measurement for the tracheal tube and laryngeal mask. The developed device is a portable medical device for monitoring the air pressure in the pilot balloon used in operating rooms and intensive care units. The cuff pressure values measured in the tracheal tube or laryngeal mask can be transferred simultaneously to the display and memory card on the device. It gives an audible warning when the air pressure inside the cuff pilot balloon is outside the allowable range of pressure values. The device was developed using an embedded microcontroller based system board and barometric pressure-gauge. Pressure measurements were tested on infant and child phantoms in-vitro and statistical analysis was performed with the actual data obtained.
\end{abstract}

Key words: Endotracheal tube, laryngeal mask, cuff pressure measurement, electronics device.

\section{Giriş}

Laringeal maske, hipofarenksin şekline uygun olan ve larinksi kapatan minyatür bir silikon maske ile birleşmiş olan silikon bir tüpten oluşur. Trakeal tüp ile farkları sadece uç kısımlarında bulunmaktadır. Her ikisi içinde kanalın çevresinde şişirilebilir eliptik hava yastığı mevcuttur ve basınçlı bir balon olan kaf basıncı olarak adlandırılan hava yastığı kontrol ile edilirler. Yoğun bakım izlemleri ve genel anestezi uygulamaları süresince trakeal tüp ve laringeal maske kullanımı ile hava yolunun açık kalması sağlanırken, uygun kaf basıncı sağlanmadığında komplikasyonlara neden olduğu ilgili bilimsel yazında rapor edilmiştir [1-5]. Trakeal tüpte kaf basıncı ölçümü ve modifiyeli Mallinkrodt Hi-Lo jet havalandırma düzenleyici [1], kaf basıncı şırınga şişirme yöntemi ve kaf kontrolörü ile karşılaştırma [2], genel anestezi esnasında elle ve otomatik yapılan kaf basınç kontrolü karşılaştırma [3] çalışmalarında düzenli olarak sürekli ölçüm ve kaf kontrolünün önemi sunulmuştur. Kaf basıncı ile ilgili komplikasyonların değerlendirilmesi ve çözüm önerilerinde endotrakeal entübasyon deneme sayısının az olması ve kaf basıncının sürekli ölçülerek izlenmesi önerilmiştir $[4,5]$. Trakeal tüp ve laringeal maske kullanımında yumuşak doku perfüzyonunu azaltmamak ve dokuda hasar oluşturmamak için kafin uygun olan en düşük basınçta olması sağlanır. Trakeal tüp ve laringeal maske kaf basıncı değeri 10-35mmHg olarak verilmiştir [6], ayrıca bazı çalışmalarda en yüksek değerin $80-100 \mathrm{mmHg}$ olabileceği belirtilmiştir [7].

Trakeal tüp pilot balonunun elle yapılan balon kontrol uygulamalarının kaf basıncını düşürdüğü belirtilmiştir [8]. Kaf basıncının elektronik cihazla ölçüldüğü randomize kontrollü çapraz bir çalışmada,

\footnotetext{
* Sorumlu yazar: sahin.savas@yahoo.com. Yazarların ORCID Numaralar1: ${ }^{1}$ 0000-0002-4224-9643, ${ }^{2}$ 0000-0003-0284-0241, ${ }^{3}$ 0000-00032065-6907
} 
değerlendirilen kaf basınç ölçerin kritik yoğun bakım hastalarında 48 saat içinde sürekli kaf basıncının kontrolünde etkili olduğu rapor edilmiştir [9]. Anestezi altında elektronik cihazla izlenen kaf basınç ölçümlerinin operasyon esnasında daha uygun olacağı gösterilmiştir [10]. Kaf basıncı ölçümü için ticari olarak satılan elektronik cihazlar maliyet açısından gelişmekte olan ülkeler için nadir tercih edilen cihazlardır [11]. Bu nedenle, alternatif bir yöntem olan geleneksel invazif kan basınç monitör dönüştürücü ile endotrakeal tüp kaf basıncı ölçme tekniği kullanılabilmektedir $[12,13]$. Ancak hasta monitöründe kan basıncı ölçme özelliği kaf basıncı ölçmek için kullanıldığında, eş zamanlı olarak kan basıncı ölçme seçeneği kullanılamamaktadır.

Bu çalışmada, mikro-kontrolör tabanlı elektronik kart geliştirilerek, endotrakeal tüp ve laringeal maske için kaf basıncı ölçme cihazı düşük maliyetli olarak tasarlanmıştır. Cihaz üzerindeki mini-LCD ekran üzerinden ve veri iletişim seçenekleri ile bilgisayar veya bir mobil cihaza veri aktarılabilir. Oluşan fazla basıncı düşürmek amacıyla sesli uyarı sistemi ile tahliye vanası kullanılabilir. Ölçülen veriler in-vitro olarak alınmış ve cihaz test edilmiştir.

Çalıșmanın geri kalan bölümleri sırasıyla dört bölüm olarak sunulmuştur. İkinci bölümde kaf basıncı tanımı ve ölçülmesi açıklanmıştır. Üçüncü bölümde gerçek zamanlı veri ölçümü yapan mikro-kontrolör tabanlı elektronik cihaz tasarımı sunulmuştur. Dördüncü bölümde tasarlanan sistem in-vitro olarak test edilmiş, istatistiksel analizle sonuçlar anlatılmıştır. Son bölümde, cihazın tasarımında elde edilen sonuçlar ve olası gelecek çalışmalar değerlendirilmiştir.

\section{Kaf Basıncı ve Ölçümü}

Trakeal tüp ve laringeal maske kullanımında kaf basıncı değerlerinin çocuk ve yetişkinler için uygun değerlerde ayarlanması ve düzenli olarak kontrol edilip hasta hava yolunun açık kalması önemlidir [14-16]. Yapısal olarak laringeal maske hipofarenksin yapısına uygun ve larinksi kapatan bir silikon maske ile belli bir açıda silikon tüple birleştirilmiş yapıdadır (Şekil 1). Maske çevresinde bulunan laringeal maske kafı basıncı pilot balonu ile kontrol edilir. Basınç değerinin 50-70 $\mathrm{cmH}_{2} \mathrm{O}$ aralığında olması sağlanır [14-16]. Laringeal maske, tek kullanımlık olup, yetişkin ve çocuk için farklı boyutları bulunmaktadır.

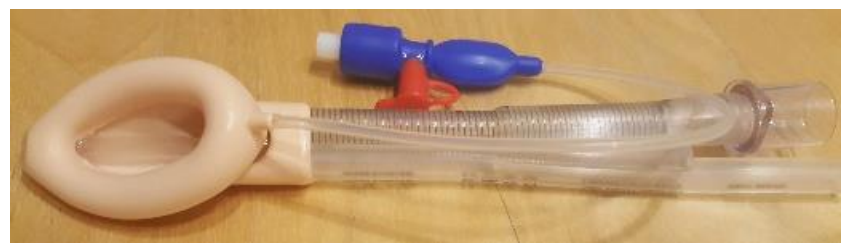

Şekil 1. Tipik bir Laringeal maske

Benzer bir yapıda olan trakeal tüp kafi, trakeal tüp çevresinde bulunur ve pilot balon ile bu kaf basınc1 kontrol edilir (Şekil 2). Sırasıyla çocuk ve yetişkinlerde 20-30 $\mathrm{cm} \mathrm{H}_{2} \mathrm{O}$ basınç değerinin geçilmemesi istenir [1316]. Trakeal tüpler tek kullanımlık olup, yetişkin ve çocuklar için farklı boyutlardadırlar.

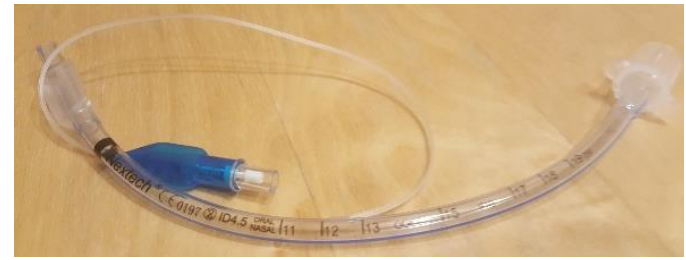

Şekil 2. Tipik bir trakeal tüp

Trakeal tüp ve laringeal maske uygulamalarında olası kaf basıncının düşmesi ve buna bağlı olarak hastanın yeterli havalanmaması problemini ortadan kaldırmak için pilot basıncın sürekli takip edilmesi gerekmektedir. Elle veya elektronik cihazla kaf basıncı ölçme işleminde, istenen değerlerde yeşille boyanmış ekran üzerinde olması veya belirli değerin dışına çıkması durumunda ikaz vermesi sağlanmıştır (Şekil 3). 


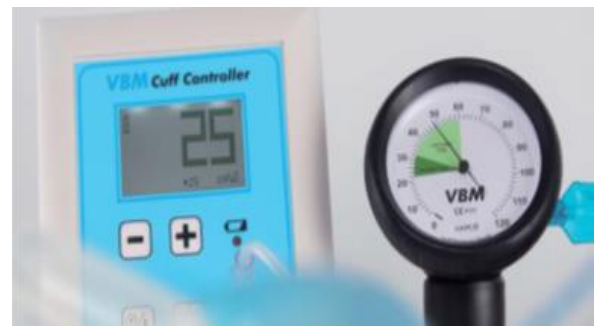

Şekil 3. Elektronik ve elle kaf kontrol cihazları [16]

\section{Kaf Basıncı Ölçme Cihazının Gerçeklemesi}

Bu çalışma kapsamında tasarlanan kaf basıncı ölçme cihazı, basınç algılayıcı ve gömülü sistem tabanlı elektronik bir cihaz olarak gerçeklenmiştir (Şekil 4). Mikro-kontroller tabanlı bir Arduino gömülü sistem kartı [17] ve çevre birimlerine bağlı hafıza ara birimi, oled ekran, BMP180 basınç algılayıcı [18], butonlar, uyarı zili ve ledlerle tasarlanmıştır.

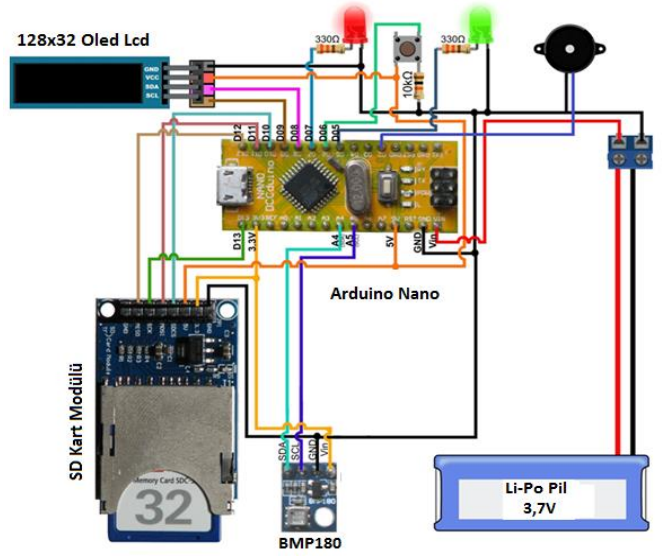

Şekil 4. Tasarlanan cihazın sadeleştirilmiş devre şeması

Cihaz birden fazla Arduino kart ve uç birimlerle haberleşmek için kullanılan seri haberleşme protokolü Inter Integrated Circuit (I2C) ile tasarlanmıştır. Kısa mesafe ve düşük veri aktarım hızı tercih edilen yerlerde kullanılan bir protokoldür. Haberleşme için kullanılan veri hatları Şekil 5'de verilmiştir. Veri aktarımı için Serial Data Line (SDA) ve Serial Clock (SCL) bağlantıları kullanılmıştır.

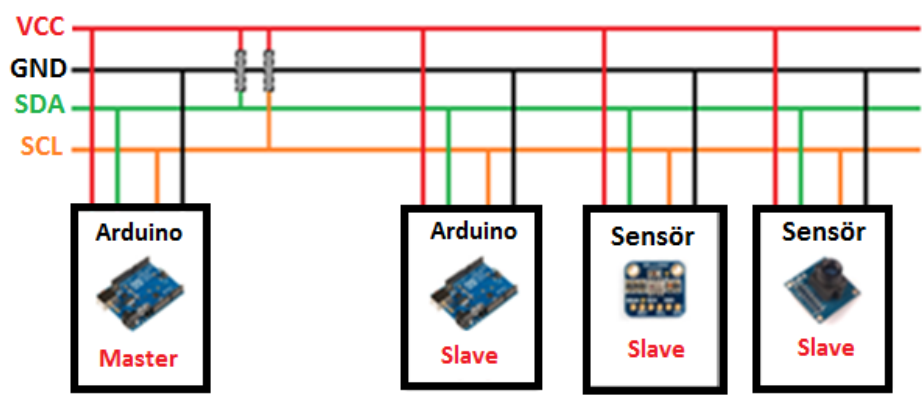

Şekil 5. I2C haberleşme protokolü bağlantısı

Tasarlanan sistemde ölçülen basınç değerleri gerekli dönüşümler yapılarak ekranda $\mathrm{mbar} / \mathrm{mmHg} / \mathrm{cm} \mathrm{H}_{2} \mathrm{O}$ olarak okunabilmektedir. Kaf basıncını pilot balondan ölçme uygulamasında sürekli olarak basınç değerini ölçerek ekranda gösterir ve basınç değerinin istenilen sınırlar dışına çıkması durumunda sesli uyarı verir. Hava 
basıncı regülasyonu, enjektör aracılığıyla elle veya otomatik kontrol döngüsü kullanan mini pompa ile düzenlenebilir. Tasarlanan cihazın ilk örnek gerçeklemesi Şekil 6'da verilmiştir. Cihaz beslemesi için USB üzerinden şarj edilebilen 3,7V Li-Po pil kullanılmıştır. Ayrıca ölçülen basınç değerleri hafıza kartına da kaydedilir.

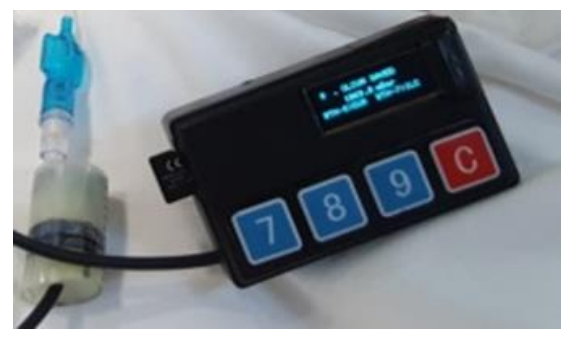

Şekil 6. Tasarlanan cihazın ilk örnek gerçeklemesi

\section{Deneysel Uygulama ve Tanımlayıcı İstatistik Analizi}

Bu çalışmada deneysel doğrulama için, tasarlanan cihazla in-vitro olarak yapılan laringeal maske ve trakeal tüp uygulamalarının bebek ve çocuk fantom maketler üzerinde sınanması ve gerçek basınç ölçme düzeneği görselleri Şekil 7'de verilmiştir. Kaf basınç ölçüm probu, laringeal maske veya trakeal tüpün kaf balonu şişirmek için kullanılan mavi renkle gösterilen "pilot balon" ucuna bağlanmaktadır. Ayrıca, mavi renkli pilot balon ucundan ölçüm alınabilmesi için basınç algılayıcısının içinde olduğu içi silikonla doldurulmuş enjektör ucu bağlantı aparatı yapılmıştır.

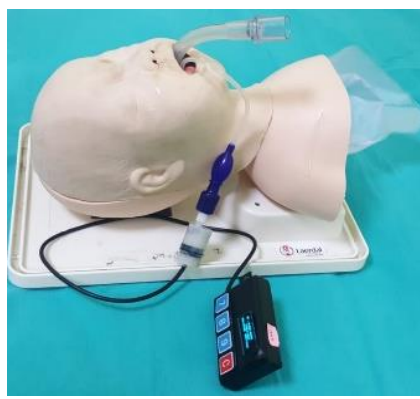

(a)

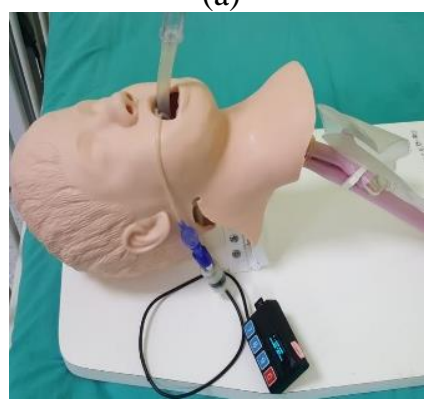

(c)

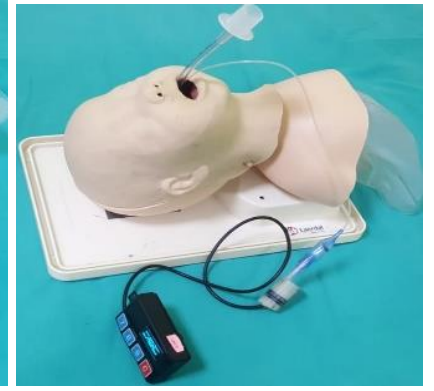

(b)

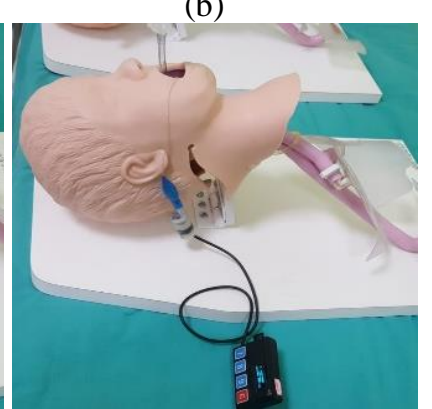

(d)

Şekil 7. Tasarlanan cihazla in-vitro olarak fantomlardan basınç ölçülmesi işlemi (a) bebek larengeal mask,

(b)bebek trakeal tüp, (c) çocuk larengeal mask, (d) çocuk trakeal tüp

Fantomlardan alınan verilerin örnekleme zamanı 15s olarak yapılandırılmış, ölçüm sayısı ve basınç değerleri ile birlikte elde edilen veriler metin belgesi olarak Tablo 1'deki gibi bir biçimde hafıza kartına aktarılmaktadır. Fantomlardan alınan verilerin zamana göre değişimleri Şekil 8'de verilmiştir. Laringeal maske ve trakeal tüp için başlangıç basınç değerleri bebekler ve çocuklar için sirasıyla $63 \mathrm{~cm} \mathrm{H}_{2} \mathrm{O}-66 \mathrm{~cm} \mathrm{H}_{2} \mathrm{O}$ ve $26 \mathrm{~cm} \mathrm{H}_{2} \mathrm{O}-29 \mathrm{cmH}_{2} \mathrm{O}$ olarak uygulanmıştır. 
Hakan ESER, Kübra EVREN ŞAHIN, Savaș ŞAHIN

Tablo 1. Hafiza kartına aktarılan örnek veri seti

\begin{tabular}{|c|c|c|}
\hline Zaman (sa:dk:sn) & Ölçüm sayısı & Basınç değeri \\
\hline $0: 0^{\prime}: 0 "$ & 1. & $25.9 \mathrm{cmH}_{2} \mathrm{O}$ \\
\hline $0: 0^{\prime}: 15^{\prime \prime}$ & 2. & $25.8 \mathrm{cmH}_{2} \mathrm{O}$ \\
\hline$\ldots$ & $\ldots$ & $\ldots$ \\
\hline
\end{tabular}

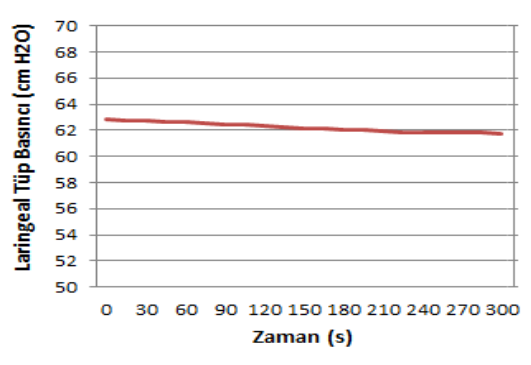

(a)

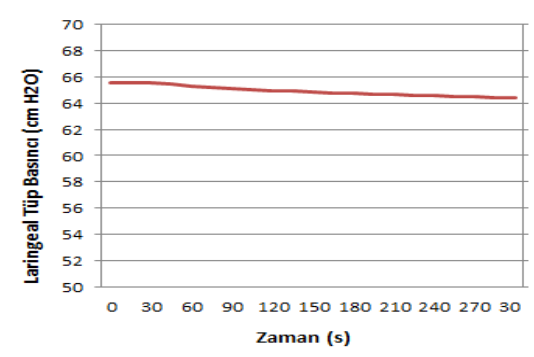

(c)

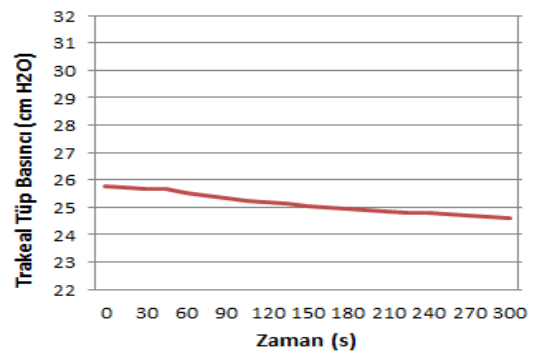

(b)

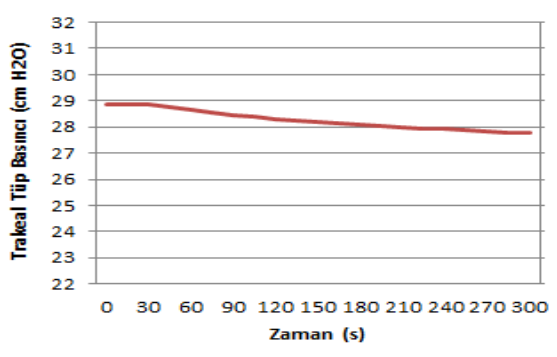

(d)

Şekil 8. In-vitro olarak fantomlardan ölçülen basınçların zaman göre değişimleri (a) bebek laringeal maske, (b) bebek trakeal tüp, (c) çocuk laringeal maske, (d) çocuk trakeal tüp

Bebek ve çocuk fantomlarından ölçülen gerçek laringeal maske ve trakeal tüp basınç değerleri SPSS paket istatistik programı ile tanımlayıcı analiz açısından değerlendirmek için her bir deneye ait olan 21 verinin istatistik olarak en küçük, en büyük, aralık, ortalama, standart hata, standart sapma ve varyans değerleri hesaplanmıştır. Tablo 2'de her dört uygulama için sunulan sonuçlar; i) bebek laringeal maske için kaf basıncının ortalama değeri $62,2386 \mathrm{cmH}_{2} \mathrm{O}$, ii) bebek trakeal tüp için kaf basıncının ortalama değeri $25,1262 \mathrm{cmH}_{2} \mathrm{O}$, iii) çocuk larengeal maske için kaf basıncının ortalama değeri 64,9343 $\mathrm{cmH}_{2} \mathrm{O}$, ve iv) çocuk trakeal tüp için kaf basıncının ortalama değeri $28,2638 \mathrm{cmH}_{2} \mathrm{O}$ değerleri olarak hesaplanmıştır.

Tablo 2. Ölçüm sonuçlarına göre tanımlayıcı istatistik sonuçları

\begin{tabular}{|c|c|c|c|c|c|c|c|c|}
\cline { 2 - 8 } \multicolumn{1}{c|}{} & Sayı & Aralık & $\begin{array}{c}\text { En } \\
\text { Küçük }\end{array}$ & $\begin{array}{c}\text { En } \\
\text { Büyük }\end{array}$ & Ortalama & $\begin{array}{c}\text { Standart } \\
\text { Hata }\end{array}$ & $\begin{array}{c}\text { Standart } \\
\text { Sapma }\end{array}$ & Varyans \\
\hline Bebek laringeal maske & 21 & 1,03 & 61,78 & 62,81 & 62,2386 &, 07841 &, 35931 &, 129 \\
\hline Bebek trakeal tüp & 21 & 1,13 & 24,62 & 25,75 & 25,1262 &, 08309 &, 38076 &, 145 \\
\hline Cocuk laringeal maske & 21 & 1,14 & 64,42 & 65,56 & 64,9343 &, 08494 &, 38925 &, 152 \\
\hline Cocuk trakeal tüp & 21 & 1,11 & 27,76 & 28,87 & 28,2638 &, 08270 &, 37897 &, 144 \\
\hline
\end{tabular}




\section{Sonuç}

$\mathrm{Bu}$ çalışmada trakeal tüp ve laringeal maske için gerçek zamanlı kaf basıncı ölçmeyi sağlayan medikal cihaz mikro denetleyici tabanlı bir gömülü sistem kartı ile gerçeklenmiştir. Kaf basıncı ölçümü için mevcut olan sürekli veri toplama özelliği olan elektronik cihazlar maliyet açısından mekanik olanlarına göre fiyatları yüksektir. $\mathrm{Bu}$ nedenle, bazı uygulamalarda alternatif yöntem olan geleneksel invazif kan basınç monitör dönüştürücü ile endotrakeal tüp kaf basıncı ölçme tekniği de kullanılmaktadır. Ancak monitörde bu özellik kullanıldığında kan basıncı ölçme seçeneği kullanılamamaktadır. Tasarlanan cihazla düşük maliyetli kaf basıncı ölçer cihazı yapılarak, pilot balon içindeki hava basıncının gerçek zamanlı ve sürekli izlenmesi sağlanmış ve bu verileri cihaz ekranı ve hafıza kartına aktarmak da mümkün olmaktadır. Ölçülen basınç ölçümleri in-vitro olarak bebek ve çocuk fantomlar üzerinden doğrulanmış, alınan gerçek verilerle tanımlayıcı istatistik analiz yapılmıştır. Tasarlanan cihazın ameliyatlar ve yoğun bakımda güvenli havayolu sağlanmasına ve entübasyon esnasındaki olumsuzlukların en aza indirilmesine yardımcı olduğunu göstermektedir.

\section{Kaynaklar}

[1] Miller DM. A pressure regulator for the cuff of a tracheal tube. Anaesthesia 1992; 47(7): 594-596.

[2] Cobley M, Kidd JF, Willis BA, Vaughan RS. Endobronchial cuff pressures. BJA: British Journal of Anaesthesia 1993; 70(5): 576-578.

[3] Tandan M, Uttam RT, Usha KB. Endotracheal tube cuff pressure monitoring during general anesthesia - A comparison between manual vs. automatic method. International Journal of Scientific Research 2018; 7(6): 36-37.

[4] Gündoğan K, Coşkun R, Güven M, Sungur M. Yoğun bakımda endotrakeal entübasyon komplikasyonlari. Dahili ve Cerrahi Bilimler Yoğun Bakım Dergisi, 2011;2(2): 39-43.

[5] Ünsal Ö, Seyhun N, Türk B, Ekici M, Dobrucalı H, Turgut S. Entübasyona sekonder üst hava yolu komplikasyonlarının değerlendirilmesi: Balon basınç manometresine karşı konvansiyonel palpasyon metodu. Şişli Etfal Tıp Bülteni 2018; 52(4):289-295.

[6] Uçgun İ. Mekanik ventilasyon komplikasyonları. Yoğun Bakım Dergisi 2008; 8(1): 44-59.

[7] Willis BA, Latto IP, Dyson A. Tracheal tube cuff pressure: clinical use of the Cardiff Cuff Controller. Anaesthesia 1988; 43(4), 312-314.

[8] Aeppli N, Lindauer B, Steurer MP, Weiss M, Dullenkopf A. Endotracheal tube cuff pressure changes during manual cuff pressure control manoeuvres: An in-vitro assessment. Acta Anaesthesiologica Scandinavica, 2019; 63(1): 55-60.

[9] Rouzé A, De Jonckheere J, Zerimech F, Labreuche J, Parmentier-Decrucq E, Voisin B, Jaillette E, Maboudou P, Balduyck M, Nseir S. Efficiency of an electronic device in controlling tracheal cuff pressure in critically ill patients: A randomized controlled crossover study. Annals of intensive care 2016; 6(93): 1-8.

[10] Ashman RE, Appel SJ, Barba AJ. Effectiveness of interventions to increase provider monitoring of endotracheal tube and laryngeal mask airway cuff pressures. AANA Journal 2017; 85(2): 98-103.

[11] 07 Ocak 2020. [Çevrimiçi]. Erișim: https://www.hamilton-medical.com/en_US/Products/Accessories-andConsumables/IntelliCuff.html

[12] Ganigara A, Ramavakoda CY. Continuous real time endotracheal tube cuff pressure waveform. Journal of Clinical Monitoring and Computing 2014; 28(4): 433-434

[13] Kim JB, Lee JM. A simple and widely available alternative method for endotracheal tube cuff pressure monitoring. Canadian Journal of Anesthesia 2018; 65(8): 956-957.

[14] Abdelatti MO. A cuff pressure controller for tracheal tubes and laryngeal mask airways. Anaesthesia 1999; 54(10): 981986.

[15] Ong M, Chambers NA, Hullet B, Erb TO, Von Ungern-Sternberg BS. Laryngeal mask airway and tracheal tube cuff pressures in children: are clinical endpoints valuable for guiding inflation? Anaesthesia 2008; 63(7): 738-744.

[16] 07 Ocak 2020. [Çevrimiçi]. Erişim:https://www.vbm-medical.com/products/airway-management/

[17] 07 Ocak 2020. [Çevrimiçi]. Erişim: https://www.arduino.cc/en/Main/Products

[18] 07 Ocak 2020. [Çevrimiçi]. Erişim: https://www.adafruit.com/product/1603 